well as our own experience, demonstrate the reluctance of physicians to up-titrate nitroglycerin doses, especially in patients being treated without hemodynamic monitoring. ${ }^{1}$ Our findings also reflect the temporary nature of the nitrate-induced hemodynamic effect because of the early development of tolerance ${ }^{8,9}$ Attenuation of effect with continuous vascular exposure to nitrates has recently been suggested to be caused by increased production of oxygen-free radicals, which leads to decreased bioavailability of nitrate-derived nitric oxide ${ }^{10,11}$ and a negative effect on the function of nitric oxide synthase, the enzyme responsible for endothelial control of vascular tone. ${ }^{12,13}$

This study represents a subgroup analysis of data from 1 individual center participating in the VMAC study. As such, the results are limited by a relatively small sample size and the derivative experience. In addition, although the maximum mean dose of nitroglycerin used at this site was high relative to that for all sites participating in the VMAC study, even higher doses may be used in clinical practice. Higher doses of nitroglycerin may have similar or different clinical outcomes.

1. Publication Committee for the VMAC Investigators (Vasodilation in the Management of Acute $\mathrm{CHF}$ ). Intravenous nesiritide vs nitroglycerin for treatment of decompensated congestive heart failure: a randomized controlled trial. JAMA 2002;287:1531-1540.

2. Colucci WS, Elkayam U, Horton DP, Abraham WT, Bourge RC, Johnson AD,
Wagoner LE, Givertz MM, Liang CS, Neibaur M, et al. Intravenous nesiritide, a natriuretic peptide, in the treatment of decompensated congestive heart failure. Nesiritide Study Group. N Engl J Med 2000;343:246-253.

3. Magrini F, Niarchos AP. Ineffectiveness of sublingual nitroglycerin in acute left ventricular failure in the presence of massive peripheral edema. Am J Cardiol 1980;45:841-847.

4. Kulick D, Roth A, McIntosh N, Rahimtoola SH, Elkayam U. Resistance to isosorbide dinitrate in patients with severe chronic heart failure: incidence and attempt at hemodynamic prediction. J Am Coll Cardiol 1988;12:1023-1028.

5. Katz SD, Biasucci L, Sabba C, Strom JA, Jondeau G, Galvao M, Solomon S, Nikolic SD, Forman R, LeJemtel TH. Impaired endothelium-mediated vasodilation in the peripheral vasculature of patients with congestive heart failure. $J \mathrm{Am}$ Coll Cardiol 1992;19:918-925.

6. Elkayam U, Mehra A, Shotan A, Ostrzega E. Nitrate resistance and tolerance: potential limitations in the treatment of congestive heart failure. Am J Cardiol 1992;70(suppl):98B-104B.

7. Elkayam U, Karaalp IS, Wani OR, Tummala P, Akhter MW. The role of organic nitrates in the treatment of heart failure. Prog Cardiovasc Dis 1999;41:255-264.

8. Elkayam U, Kulick D, McIntosh N, Roth A, Hsueh W, Rahimtoola SH. Incidence of early tolerance to hemodynamic effects of continuous infusion of nitroglycerin in patients with coronary artery disease and heart failure. Circulation 1987;76:577-584.

9. Dupuis J, Lalonde G, Lemieux R, Rouleau JL. Tolerance to intravenous nitroglycerin in patients with congestive heart failure: role of increased intravascular volume, neurohumoral activation and lack of prevention with $\mathrm{N}$-acetylcysteine. J Am Coll Cardiol 1990;16:923-931.

10. Gori T, Parker JD. The puzzle of nitrate tolerance: pieces smaller than we thought? Circulation 2002;106:2404-2408.

11. Gori T, Parker JD. Nitrate tolerance: a unifying hypothesis. Circulation 2002;106:2510-2513.

12. Munzel T, Hink U, Yigit H, Macharzina R, Harrison DG, Mulsch A. Role of superoxide dismutase in in vivo and in vitro nitrate tolerance. $\mathrm{Br} J$ Pharmacol 1999;127:1224-1230.

13. Gori T, Mak SS, Kelly S, Parker JD. Evidence supporting abnormalities in nitric oxide synthase function induced by nitroglycerin in humans. J Am Coll Cardiol 2001;38:1096-1101

\title{
Meta-Analysis of Effectiveness or Lack Thereof of Angiotensin-Converting Enzyme Inhibitors for Prevention of Heart Failure in Patients With Systemic Hypertension
}

\author{
Fabio Angeli, MD, Paolo Verdecchia, MD, Gian Paolo Reboldi, MD, PhD, MSc, \\ Roberto Gattobigio, MD, Maurizio Bentivoglio, MD, Jan A. Staessen, MD, PhD, and \\ Carlo Porcellati, MD
}

We undertook a meta-analysis of large, randomized controlled trials in hypertensive subjects that compared angiotensin-converting enzyme (ACE) inhibitors with different classes of antihypertensive drugs. Compared with subjects randomized to drugs different from ACE inhibitors, those treated with ACE inhibitors did not show a different risk of congestive heart failure (CHF) lodds ratio 1.03 , 95\% confidence interval 0.96 to $1.12, p=0.407$ ). The degree of protection from CHF associated with the use of ACE inhibi-

\footnotetext{
From the Department of Cardiovascular Disease, Hospital R. Silvestrini, Perugia, Italy; Dipartimento di Medicina Interna, Universitá degli Studi di Perugia, Perugia, Italy; and Laboratory of Hypertension, Department of Molecular and Cardiovascular Research, Campus Gasthuisberg, Leuven, Belgium. Dr. Verdecchia's address is: Dipartimento Malattie Cardiovascolari, Ospedale R. Silvestrini, Località S. Andrea delle Fratte, 06156 , Perugia, Italy. E-mail: erdec@tin.it. Manuscript received July 22, 2003; revised manuscript received and accepted September 18, 2003
}

tors showed a nonsignificant trend to increase with age and the degree of blood pressure control. Thus, the hypothesis that ACE inhibitors are superior to other antihypertensive drugs for prevention of CHF in hypertension remains unproven. $\odot 2004$ by Excerpta Medica, Inc.

(Am J Cardiol 2004;93:240-243)

A ngiotensin-converting enzyme (ACE) inhibitors improve symptoms and prolong survival in patients with congestive heart failure (CHF). In a metaanalysis of 7 large studies in patients with CHF or left ventricular dysfunction, ACE inhibitors were associated with a significant decrease in a composite of death, myocardial infarction, and hospital admission for patients with CHF (odds ratio [OR] 0.72, 95\% confidence interval $[\mathrm{CI}] 67$ to 78). ${ }^{1}$ However, although the benefits of ACE inhibitors in patients with $\mathrm{CHF}$ are well established, their potential value for 


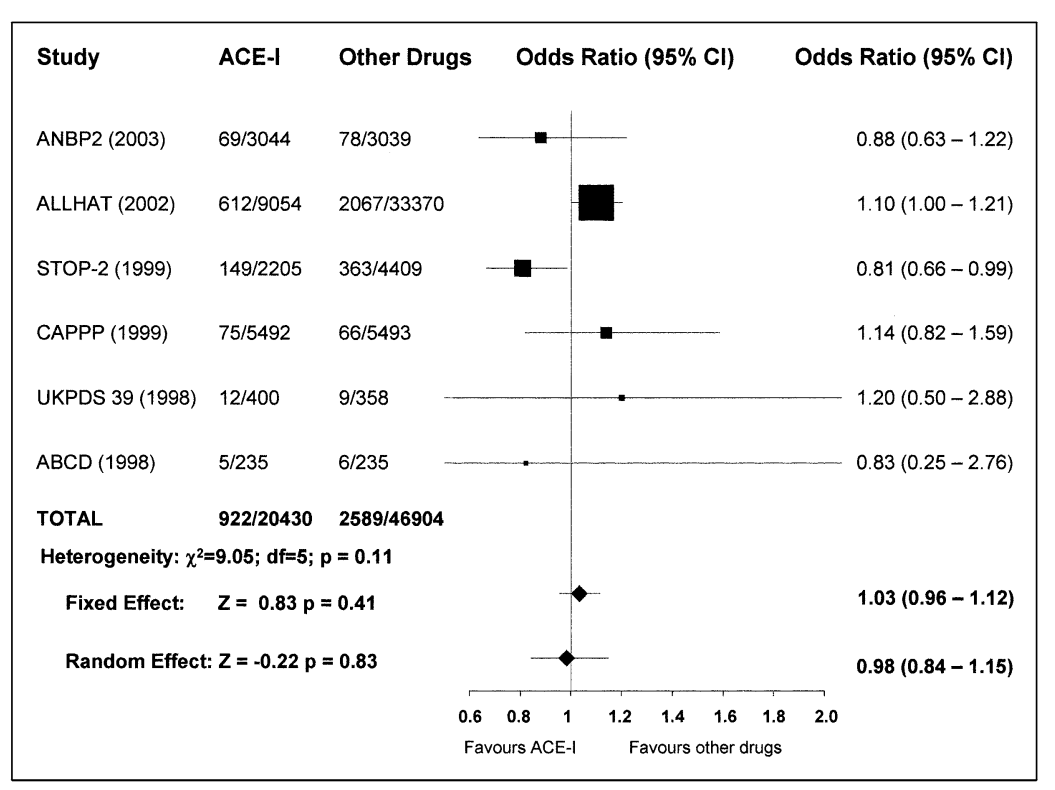

FIGURE 1. Heart failure events associated with ACE inhibitors (ACE-I) and drugs with different mechanisms of action in patients with essential hypertension. $A B C D=$ Appropriate Blood Pressure Control in Diabetes; ANBP2 = Second Australian National Blood Pressure Study Group; CAPPP = Captopril Prevention Project; STOP-2 =Swedish Trial in Old Patients with Hypertension-2 study; UKPDS = UK Prospective Diabetes Study Group.

individual reports. All outcome results were reported on the basis of an intention-to-treat approach.

The reference group was composed of patients randomly assigned to antihypertensive drugs different from ACE inhibitors. The OR and 95\% CI for CHF were calculated separately for each of the 6 studies according to fixed- and random-effect models. The assumption of homogeneity between patient studies was tested using the Zelen's test. Analyses were performed using the Comprehensive Meta-Analysis software (Biostat, Englewood, New Jersey). We used the SPSS 11.0 statistical package (SPSS Inc., Chicago, Illinois) to correlate the ORs of treatment with ACE inhibitors versus other antihypertensive drugs with the corresponding differences in achieved systolic blood pressure. For these calculations, the regression lines were weighted by the inverse of variance of patient ORs.

Table 1 lists the main characteris-

primary prevention of $\mathrm{CHF}$ in patients with hypertension is still unclear. By blunting the renin-angiotensin system over the long term, ACE inhibitors might prevent or delay progression of myocardial fibrosis and structural disarray in the hypertensive heart, ${ }^{2,3}$ and, thus may have potential valuable implications for the prevention of CHF.

We undertook a meta-analysis of major clinical trials in hypertension that compared ACE inhibitors with different antihypertensive drugs in subjects with primary hypertension. We tested whether treatment with ACE inhibitors was associated with a lower risk of CHF. We selected only the studies that met all of the following prespecified criteria: (1) publication in a peer-reviewed journal indexed in MEDLINE; (2) inclusion of patients with a clinical diagnosis of essential hypertension; (3) occurrence of CHF as a prespecified end point during follow-up; (4) definition of CHF events in the single studies; (5) assessment of blood pressure at baseline and at follow-up visits; (6) randomized controlled design; (7) follow-up of $\geq 2$ years; and (8) sample size $\geq 100$ subjects.

Studies were identified through MEDLINE using research methods filters ${ }^{4}$ with publication dates before June 30, 2003. The final search identified 6 studies $^{5-11}$ that fulfilled the inclusion criteria. Two of these studies had enrolled patients with hypertension and type 2 diabetes. ${ }^{8,9}$ The Analysis of the Antihypertensive and LipidLowering Treatment to Prevent Heart Attack Trial (ALLHAT) included the reports published in $2000^{6}$ and $2002^{7}$ to allow an assessment of the effects of doxazosin ${ }^{6}$ in addition to other treatments. ${ }^{7}$ For all studies, we accepted the definition of CHF events reported in the tics of the clinical trials. All of the trials-except the Appropriate Blood Pressure Control in Diabetes ${ }^{9}$ study, which enrolled patients affected by type 2 diabetes with or without hypertension-were conducted in subjects with hypertension. For the purpose of the present analysis, we included only the cohort of subjects with hypertension. The age of subjects ranged from 52 to 73 years, and male gender prevailed (range $33 \%$ to $55 \%$ ). The duration of follow-up ranged from 4.1 to 8.4 years. At randomization, none of the subjects had clinical evidence of CHF in most studies, ${ }^{4-8}$ whereas $0.3 \%$ of subjects in 1 study ${ }^{11}$ and $1.9 \%$ of subjects in another study ${ }^{10}$ had a previous diagnosis of CHF.

Overall, there were 3,511 new cases of CHF: 922 among the subjects randomized to ACE inhibitors and 2,589 among the subjects randomized to other antihypertensive drugs. The risk of CHF did not differ between subjects randomized to receive ACE inhibitors and subjects randomized to receive different classes of antihypertensive drugs (fixed effect: OR 1.03, 95\% CI 0.96 to $1.12 ; \mathrm{p}=0.407$; random effect: OR $0.98,95 \%$ CI 0.84 to $1.15 ; \mathrm{p}=0.83$ ) (Figure 1). Because of its large sample size, ALLHAT ${ }^{6,7}$ exerted a major influence on the overall meta-analysis estimate. For example, the OR for CHF in the lisinopril groups compared with the other nonACE groups in ALLHAT was 1.10 (95\% CI 1.00 to 1.21 ) with a $\mathrm{p}$ value bordering on significance $(\mathrm{p}=$ 0.050 ). The percentage weight contributed by ALLHAT to the overall metaanalysis was $68.7 \%$.

In patient studies, the degree of protection from CHF, expressed in terms of OR in the ACE inhibitor group compared with the other group, showed a nonsignificant trend to increase with age $\left(\mathrm{R}^{2}=0.38\right)$ and a nonsignificant trend to decrease with achieved sys- 
TABLE 1 Characteristics of Trials Comparing Angiotensin-Converting Enzyme (ACE) Inhibitors With Different Antihypertensive Drugs

\begin{tabular}{|c|c|c|c|c|c|c|}
\hline Characteristics & UKPDS 398 & $A B C D^{9}$ & STOP-2 ${ }^{10}$ & CAPPP 11 & ALLHAT6,7 & ANBP2 5 \\
\hline Yr of publication & 1998 & 1998 & 1999 & 1999 & 2000,2002 & 2003 \\
\hline Diabetes mellitus & + & + & - & - & - & - \\
\hline \multicolumn{7}{|l|}{ Demographic characteristics } \\
\hline No. of patients (ACE-I/others) & $400 / 358$ & $235 / 235$ & $2,205 / 4,409$ & $5,492 / 5,493$ & $9,054 / 24,316$ & $3,044 / 3,039$ \\
\hline Age in years (ACE-I/others) & $56.3 / 56.0$ & $57.7 / 57.2$ & $76.1 / 75.9$ & $52.4 / 52.7$ & $66.9 / 66.9$ & $72 / 72.9$ \\
\hline$\%$ Men (ACE-I/others) & $51 / 57$ & $50 / 47$ & $34 / 33$ & $55 / 52$ & $46 / 47$ & $50 / 48$ \\
\hline \multicolumn{7}{|l|}{ Type of treatment } \\
\hline ACE-I & Captopril & Enalapril & Enalapril/lisinopril & Captopril & Lisinopril & Enalapril \\
\hline Reference drugs & Atenolol & Nisoldipine & $\begin{array}{l}\beta \text { blockers/diuretic/ } \\
\text { CCB }\end{array}$ & $\beta$-blockers/diuretic & $\begin{array}{l}\text { Amlodipine/chortalidone/ } \\
\text { doxazosin }\end{array}$ & Diuretics \\
\hline Add-on drugs & $\begin{array}{l}\text { Furosemide, nifedipine, } \\
\text { methyldopa, } \\
\text { prazosin }\end{array}$ & Metoprolol, diuretics & Diuretics, $\beta$ blockers & $\begin{array}{l}\text { Ca-antagonists, } \\
\text { diuretics }\end{array}$ & $\begin{array}{l}\text { Atenolol, idralazine, } \\
\text { resrpine, clonidine }\end{array}$ & $\begin{array}{l}\beta \text {-blockers, Ca- } \\
\text { antagonists, } \\
\alpha \text {-blockers }\end{array}$ \\
\hline \multicolumn{7}{|l|}{ No. of CHF events during follow-up } \\
\hline $\begin{array}{l}\text { Systolic BP at baseline in } \mathrm{mm} \mathrm{Hg} \\
\text { (ACE-I/others) }\end{array}$ & $\begin{array}{c}12 / 9 \\
159 / 159\end{array}$ & $\begin{array}{l}5 / 6 \\
156 / 155\end{array}$ & $\begin{array}{l}149 / 363 \\
194 / 194\end{array}$ & $\begin{array}{l}75 / 66 \\
162 / 160\end{array}$ & $\begin{array}{l}612 / 2,067 \\
146 / 146\end{array}$ & $\begin{array}{c}69 / 78 \\
167 / 168\end{array}$ \\
\hline $\begin{array}{l}\text { Difference in achieved systolic BP in } \mathrm{mm} \mathrm{Hg} \\
\text { (ACE-I minus others) }\end{array}$ & -1 & -1 & -0.5 & -3 & -1.3 & 1 \\
\hline Follow-up (yrs) & 8.4 & 5.6 & 4.5 & 6.1 & 4.9 & 4.1 \\
\hline
\end{tabular}

$\mathrm{ACE}-\mathrm{I}=$ angiotensin converting enzyme inhibitor; $\mathrm{BP}=$ blood pressure; $\mathrm{CCB}=$ calcium channel blocker; $\mathrm{CHF}=$ congestive heart failure; other abbreviations as in Figure 1 . 
tolic blood pressure $\left(\mathrm{R}^{2}=0.33\right)$. These associations were not statistically significant, possibly because of the limited numbers of reviewed studies. However, these trends raise the hypothesis that ACE inhibitors may provide greater potential benefits for CHF prevention in elderly hypertensive subjects as well as in those with a better control of systolic blood pressure who are using treatment.

Our results extend those of a recent meta-analysis by Staessen et al, ${ }^{12}$ who limited their assessment to the effects of ACE inhibitors versus conventional drugs (diuretics and/or $\beta$ blockers) in some of the trials considered in this report. The risk of CHF did not differ between subjects randomized to receive ACE inhibitors and subjects randomized to receive diuretics and/or $\beta$ blockers $(p=0.64) .{ }^{12}$ Notably, our overview allows us to extend these conclusions to all antihypertensive drugs that are different from ACE inhibitors, including calcium-channel blockers and $\alpha-1$ blockers.

Although there was no significant heterogeneity across the studies (chi-square 9.05; degree of freedom $5 ; \mathrm{p}=0.11$ ), diagnoses of CHF were not uniform. In 5 studies, ${ }^{5,8,9-11}$ adjudication of CHF events was made by an independent end-point committee whose members were blinded to the treatment group. In all of these studies, adjudication of CHF required subject admission to the hospital. In 1 study, ${ }^{7}$ diagnosis of $\mathrm{CHF}$ was left up to individual investigators, with $1.9 \%$ of CHF events in that study ${ }^{7}$ reviewed by a committee. ${ }^{13}$

The mean duration of follow-up, $<5$ years in half of the studies, may have been too short to disclose a protective effect of long-term ACE inhibition on the prevention of CHF. In addition, ACE inhibitors may have failed to fully suppress the activity of the reninangiotensin system during long-term treatment because of activation of other angiotensin-II-generating pathways. ${ }^{14,15}$ Angiotensin II reactivation and failure of aldosterone suppression have been found in up to $38 \%$ of patients with CHF taking an ACE inhibitor. ${ }^{14}$ These phenomena have been ascribed to poor compliance with therapy in patients with low levels of ACE inhibition or to activation of alternative angiotensinII-generating pathways in those with low ACE and high angiotensin II concentrations. ${ }^{14}$ The frequency of angiotensin II reactivation and failure of aldosterone suppression in apparently healthy subjects with essen- tial hypertension treated with ACE inhibitors are unknown.

1. Flather MD, Yusuf S, Kober L, Pfeffer M, Hall A, Murray G, Torp-Pedersen C, Ball S, Pogue J, Moye L, et al. Long-term ACE-inhibitor therapy in patients with heart failure or left-ventricular dysfunction: a systematic overview of data from individual patients. ACE-Inhibitor Myocardial Infarction Collaborative Group. Lancet 2000;355:1575-1581.

2. Brilla CG, Funck RC, Rupp H. Lisinopril-mediated regression of myocardial fibrosis in patients with hypertensive heart disease. Circulation 2000;102:13881393.

3. Weber KT, Brilla CG. Pathological hypertrophy and cardiac interstitium. Fibrosis and renin-angiotensin-aldosterone system. Circulation 1991;83:18491865 .

4. Haynes RB, Wilczynski N, McKibbon KA, Walker CJ, Sinclair JC. Developing optimal search strategies for detecting clinically sound studies in MEDLINE. J Am Med Inform Assoc 1994;1:447-458.

5. Wing LM, Reid CM, Ryan P, Beilin LJ, Brown MA, Jennings GL, Johnston CI, McNeil JJ, Macdonald GJ, Marley JE, et al. A comparison of outcomes with angiotensin-converting-enzyme inhibitors and diuretics for hypertension in the elderly. N Engl J Med 2003;348:583-592.

6. The ALLHAT Officers and Coordinators for the ALLHAT Collaborative Research Group. Major cardiovascular events in hypertensive patients randomized to doxazosin vs chlorthalidone: the Antihypertensive and Lipid-Lowering Treatment to Prevent Heart Attack Trial (ALLHAT). JAMA 2000;283:19671975.

7. The ALLHAT Officers and Coordinators for the ALLHAT Collaborative Research Group. The Antihypertensive and Lipid-Lowering Treatment to Prevent Heart Attack Trial. Major outcomes in high-risk hypertensive patients randomized to angiotensin-converting enzyme inhibitor or calcium channel blocker vs diuretic: The Antihypertensive and Lipid-Lowering Treatment to Prevent Heart Attack Trial (ALLHAT). JAMA 2002;288:2981-2987.

8. UK Prospective Diabetes Study Group. Efficacy of atenolol and captopril in reducing risk of macrovascular and microvascular complications in type 2 diabetes: UKPDS 39. BMJ 1998;317:713-720.

9. Estacio RO, Jeffers BW, Hiatt WR, Biggerstaff SL, Gifford N, Schrier RW. The effect of nisoldipine as compared with enalapril on cardiovascular outcomes in patients with non-insulin-dependent diabetes and hypertension. $N$ Engl J Med 1998;338:645-652.

10. Hansson L, Lindholm LH, Ekbom T, Dahlof B, Lanke J, Schersten B, Wester PO, Hedner T, de Faire U. Randomised trial of old and new antihypertensive drugs in elderly patients: cardiovascular mortality and morbidity. The Swedish Trial in Old Patients with Hypertension-2 study. Lancet 1999;354:1751-1756.

11. Hansson L, Lindholm LH, Niskanen L, Lanke J, Hedner T, Niklason A, Luomanmaki K, Dahlof B, de Faire U, Morlin C, et al. Effect of angiotensinconverting-enzyme inhibition compared with conventional therapy on cardiovascular morbidity and mortality in hypertension: the Captopril Prevention Project (CAPPP) randomized trial. Lancet 1999;353:611-616.

12. Staessen JA, Wang J-G, Thijs L. Cardiovascular prevention and blood pressure reduction: a quantitative overview updated until 1 March 2003. J Hypertens 2003;21:1056-1076.

13. Piller LB, Davis BR, Cutler JA, Cushman WC, Wright JT Jr., Williamson JD, Leenen FH, Einhorn PT, Randall OS, Golden JS, et al. Validation of heart failure events in the Antihypertensive and Lipid Lowering Treatment to Prevent Heart Attack Trial (ALLHAT): participants assigned to doxazosin and chlorthalidone. Curr Control Trials Cardiovasc Med 2003;3:1-9.

14. MacFadyen RJ, Lee AF, Morton JJ, Pringle SD, Struthers AD. How often are angiotensin II and aldosterone concentrations raised during chronic ACE inhibitor treatment in cardiac failure? Heart 1999;82:57-61.

15. Morgan T, Brunner HR. The renin-angiotensin system and the heart: beyond 2000. Heart 1996;76(suppl 3):98-103. 